\title{
On the Assessment of Decision Quality: Considerations Regarding Utility, Conflict and Accountability
}

\author{
Gideon Keren \\ Eindhoven University of Technology, The Netherlands \\ and \\ Wändi Bruine de Bruin \\ Carnegie Mellon University, Pittsburgh, USA
}

During the course of their lives, people are faced with many decisions-covering a wide variety of contexts and ranging in importance. Common decision-making topics include career moves, whether to get married (and, if so, to whom and when), what house to rent (or buy), where to shop for groceries and what to have for dinner. The need for making a good decision grows as the importance of the context increases. Unfortunately, it is often not obvious what constitutes a good decision.

At the bottom line, the question of decision quality is the essence of decision sciences: a main goal of researchers in the discipline is to help improve people's decision making. Yet, with few exceptions (e.g., Edwards et al., 1984; Lipshitz, 1989, 1995; Hershey \& Baron, 1992, 1995; Frisch \& Jones, 1993; Frisch \& Clemen, 1994), this topic has received relatively little attention in the literature. Several reasons may account for the reluctance to treat it directly. First, the topic may be seen as too broad and ill-defined, rendering it virtually impossible to be treated in a systematic and concise manner. A second, related, reason may be that various classes of decisions can be defined, each requiring different judgment criteria (e.g., von Winterfeldt, 1980). Third, the discussion of "decisions about decisions" introduces the concept of second-order decision making. In turn, this would expose third-, fourth-, and fifth-order decisions, and so on ad infinitum. A similar problem was identified

Thinking: Psychological Perspectives on Reasoning, Judgment and Decision Making. Edited by David Hardman and Laura Macchi. (C) 2003 John Wiley \& Sons, Ltd. 
with the subject of second-order probabilities (Goldsmith \& Sahlin, 1982). Finally, some may claim that a satisfactory answer to the question does not yet exist. Pessimists may extend this claim to the future.

Despite the difficulties associated with assessing decision quality, some researchers have attempted to address the issue. Perhaps the most fundamental question has been whether decisions should be judged by the process (by which they were derived) or by outcome (and the associated consequences). Most have taken a process-oriented approach, often basing their advice on one version of utility theory or another (Savage, 1954; Luce \& Raiffa, 1957), and discussing how a good decision should be structured and modeled (Edwards et al., 1984; Lipshitz, 1989). The main argument for this process-based approach is that most, if not all, decisions are made under uncertainty. "A decision is therefore a bet, and evaluating it as good or not must depend on the stakes and the odds, not on the outcome" (Edwards et al., 1984, p. 7). Given the structure and numbers that enter into a decision problem, the task of decision making itself should, in principle, be trivial. The difficulty lies in obtaining the appropriate structure and problem space, reflecting all possible outcomes, the degree to which they fulfill one's goals, the contingencies between decision and outcome, and the probability of occurrence of different outcomes. The "right" decision, then, is to choose the option with the highest chance of accomplishing the decision maker's goals. The underlying assumption is that, in the long run, good decision processes are more likely to generate good outcomes.

Thus, the process-oriented approach evaluates a decision's quality by its structure, including how well it represents the decision maker's goals. As a result, it is easier to assess the quality of well- than ill-defined decision problems (Simon, 1973). When judging ill-defined problems, the focus often remains on the inadequate problem formulation rather than on the decision itself.

Most real-life decisions are vague and ill-defined (Fischhoff, 1996). Decision makers may, for example, hold multiple and ambiguous goals, making it difficult to judge what would be the best decision. Yet, process-oriented students of decision making would argue that half of the solution involves appropriate structuring of the decision problem.

Baron (1994) notes that people have difficulty in following this process-oriented approach. Normatively, the decision structure should incorporate potential outcomes, because only these affect the fulfillment of the decision maker's goals-a requirement known as "consequentialism". Even if it does not affect the consequences of a decision (in terms of their goals), people are sensitive to the manner in which an outcome has been obtained. Baron and his colleagues (e.g., Spranca, Minsk \& Baron, 1991; Ritov \& Baron, 1992) have shown that decisions with identical outcomes are judged as worse when they result from acts of commission than acts of omission. For example, most people are reluctant to vaccinate children against a potentially lethal flu when side effects of the vaccine can cause death. Faced with a flu epidemic that is expected to kill 10 out of 10000 children, most people are not willing to accept a 9 out of 10000 risk of death from vaccination, and the median acceptable maximum risk is 5 in 10000 . Apparently, killing a child with a vaccination (that is, an act of commission) is perceived as worse than causing its death by failing to vaccinate (that is, an act of omission) (Ritov \& Baron, 1990). This pattern of results poses a violation of consequentialism, unless feelings of guilt (resulting from commission but not from omission) may be included in the definition of "consequence". Indeed, some argue that strong emotional responses should be considered as part of the decision outcome (see commentaries included in Baron, 1994).

After the outcome of a decision is known, people are even less likely to follow the guidelines provided by the process-based literature. Instead, when judging decision quality, 
they tend to focus on the outcome rather than the process (Baron \& Hershey, 1988; Jones, Yurak \& Frisch, 1997). Referring to an operation as successful after the patient has died remains unsatisfactory for most laypersons. The simple reason underlying this emphasis on the outcome is that, at the end of the day, the consequences of a decision are more salient than the process that produced them.

Some researchers of behavioral decision making have defended the focus on outcomes. Hershey and Baron $(1992,1995)$ point out that if a good decision process is more likely to lead to a good outcome, it follows logically that good outcomes are more likely to stem from good decision processes. ${ }^{1}$ Frisch and Clemen (1994) take this argument further, treating the question of decision quality as entirely empirical. Any feature of the decision process that increases the probability of obtaining a good outcome thus improves the quality of the decision-even if it violates the process-oriented approach.

Yet, the majority of researchers emphasize that the process, rather than the outcome, should be the object of evaluation. Their theories are considered "normative", prescribing how people should make, and judge, decisions. "Descriptive" research, which describes how decisions are actually made, shows that people focus on decision outcomes. Normative and descriptive considerations are deeply interrelated, and there is an ongoing interplay between the two perspectives (Coombs, Dawes \& Tversky, 1970; Keren, 1996). To assess decision quality, it is important to examine both normative and descriptive facets of the relevant issues. A common procedure is to use normative benchmarks to which the actual process and outcome are compared. ${ }^{2}$ An alternative option, and the one that we recommend, is what Keeney and Raiffa (1976) termed the "prescriptive" approach. It offers guidelines to decision makers who search for optimization, yet takes into account their limited capacity for memory and information processing that makes them vulnerable to human error, reasoning biases and swaying emotions.

Which specific considerations prevail in the process of assessing decision quality depends, to a large extent, on the decision-making model that is adopted by the judge. In the following, the problem of decision quality is examined within three, broadly defined, different approaches to the study of decision making. The first is the so-called gambling paradigm, which has been the dominating metatheory in the field of decision making since its inception. Its main underlying assumption is that every decision problem can be translated into a choice between gambles, relying heavily on utility theory (e.g., Luce \& Raiffa, 1957; Keeney \& Raiffa, 1976; Schoemaker, 1982). The second approach is the conflict model, which considers a decision to be the resolution of an emotional conflict, in which to choose one option means to forego another (e.g., Janis \& Mann, 1977; Coombs, 1987). The third and last approach is the accountability model (Tetlock, 1991; Lerner \& Tetlock, 1999), which asserts that the decision maker's major goal is to defend decisions convincingly-if held accountable. Although the latter two models were not intended to be normative, each offers implicit guidelines to judge decision quality, assigning different (relative) weights to the outcome- and process-oriented approach.

This chapter emphasizes that the judge of the decision and the decision maker may not use the same framework to evaluate the decision-and, hence, may disagree. Evaluations may even vary between judges who endorse different perspectives and different models. For

\footnotetext{
${ }^{1}$ Hershey and Baron's argument that P(good outcome/good decision) corresponds "logically" to P(good decision/good outcome) actually holds only under the assumption that "bad" decisions are not more likely than "good" decisions.

2 Note that normative guidelines may vary depending on the assumptions one wants to adopt. Often, specifically with complex decisions, an unequivocal solution does not exist.
} 
example, patients and colleagues may take a different approach to judging the quality of a physician's decision. While the colleagues may emphasize the decision process, the patients will probably focus on the outcome. As suggested before, the latter will be more likely to consider a decision to operate wrongly if it leads to a death. Whatever the perspective taken, a perfectly neutral judge rarely, if ever, exists.

How a decision is assessed also depends on whether the judge focuses on the decision or the decision maker - the product or the producer. For example, a jury could judge the crime or the criminal—considering, among other things, the number of offenses. Although the two are closely linked, they are by no means the same. A focus on the decision maker may involve a review of that person's decision-making history, which incorporates multiple, repeated, decisions. Judging only a specific decision, in contrast, treats it as unique, inspiring a more narrow view. Formal normative theories (specifically different versions of utility theory, to be discussed later in this chapter) assume that there is no fundamental difference (e.g., Coombs, Dawes \& Tversky, 1970). In both cases, good decision processes have a higher chance of producing good outcomes. There is mounting empirical evidence, however, that, in practice, the decision maker's choice patterns (and, possibly, judgments of these decisions) under unique and repeated choice conditions are not necessarily the same (e.g., Lopes, 1981; Keren, 1991a; Redelmeier \& Tversky, 1992, to mention just a few). People may be hesitant to take a gamble (with positive expected value) once, but be willing to take it repeatedly (Samuelson, 1963).

Whether a decision is perceived as unique or repeated is often determined by the manner in which the decision is framed, and by who the decision maker is. For instance, a patient (or one of her relatives) who has to judge the quality of a medical treatment will naturally focus solely on the particulars of her own case, thus adopting a unique perspective. In contrast, physicians will probably tend to take into account distributional information. The dispute concerning statistical as opposed to clinical judgment (Dawes, Faust \& Meehl, 1989) suggests that while the former approach is normatively superior, most people cling to the latter. A fundamental disagreement between the decision maker and the judge may arise when one adopts the clinical while the other adopts the statistical approach (or vice versa).

In sum, the judgment of decision quality depends on the perspective taken by the judgewhether focusing on outcome or process, the decision or the decision maker, a statistical or a clinical judgment. In the rest of this chapter, we first examine pros and cons associated with the outcome- and process-oriented approach to the assessment of decision quality. We then consider the evaluation of decision quality as envisaged within each of the three metatheories mentioned above, taking into account the perspective of different judges as well as the decision maker. In the final section, we briefly summarize the different arguments and discuss the implications for daily life and future research.

\section{OUTCOME VERSUS PROCESS DELIBERATIONS IN THE EVALUATION OF DECISION QUALITY}

As mentioned, whether decisions are judged by outcome or by process may depend on the perspective of the judge. It can hardly be denied that decision processes and the corresponding outcomes are strongly interrelated. As noted by Frisch and Clemen (1994), "to evaluate decision quality, researchers need to identify those decision processes that tend 
to lead to desirable outcomes" (p. 48). Imminent decisions, then, should follow the most successful process, as apparent before they are made (that is, in foresight). However, after the decision has been made, people often mistakenly reassess the decision process in light of the outcome (Baron \& Hershey, 1988).

Indeed, knowledge of the outcome may alter perceptions of the decision, including the quality of its process. In hindsight, people consistently overestimate what could have been anticipated in foresight (Fischhoff, 1975): events that appeared irrelevant beforehand, seem to have caused the outcome after it has emerged. As a result, an unfortunate surprise outcome makes an unlucky decision maker seem incompetent, as in the case of the unforeseen (but, in hindsight, obvious) attack on Pearl Harbor (Wohlstetter, 1962). Outcome knowledge may affect the assessment of what the decision maker should have known (for example, possible outcomes and corresponding probabilities), evoking criticism especially when the outcome is disadvantageous.

Evaluation both by process and by outcome may be vulnerable to the hindsight bias. In retrospect, people may be good at constructing counterfactuals (Roese \& Olson, 1995) of how both the decision process and the corresponding outcome could have been better. In particular, "close" counterfactuals, showing that an alternative outcome "almost" happened (Kahneman \& Varey, 1990), may affect judgment and evaluation in different ways. The existence of close counterfactuals may suggest to a lenient judge that the decision maker almost got it right, whereas for a strict judge, the closeness may highlight the failure of the decision maker.

A danger of taking into account decision outcomes is that they are asymmetrical (Jones \& Nisbett, 1972). While the decision maker takes credit for good outcomes, others may not even pay attention. Bad outcomes, in contrast, lead to public outcry. Before a disastrous explosion (May, 2000) in a fireworks depot that obliterated an entire neighborhood from the map of Enschede (The Netherlands), only one citizen had formally questioned the location of the depot. The authorities refuted his objections, and the decision went unnoticed. Even if, today, the decision makers maintain that they followed a good decision process, the Dutch public holds them responsible for the horrendous disaster.

Another fundamental problem that is often manifested in using outcomes for judgment of decision quality is addressed by Einhorn and Hogarth (1978). Given a decision between two or more options, one can know for sure only the outcome (and the corresponding consequences) of the chosen option. However, the exact consequences of options that were rejected remain uncertain. Assuming, for instance, the existence of a well-defined criterion to assess job candidates, we will never know how well the rejected ones would have done. Without that outcome information, the evaluation of our decision contains an inherent component of uncertainty (which may be assessed differently by the decision maker and the judge).

The strategies underlying the decision process determine not just the outcome but can influence the evaluation of the decision itself. Specifically, Higgins $(1998,2000)$ proposed that decisions could occur under two different modes, which he termed "promotion" and "prevention". The focus under the former is the attainment of positive optimal outcomes, whereas the focus under the latter is the preclusion of total failures. Hence, the same outcome may be perceived differently depending on the mode adopted: the fact that a potential negative outcome was averted may be considered as a success under the prevention mode, yet as not sufficiently satisfactory under the promotion mode. Consequently, disagreements may arise if the decision maker and the judge have tacitly adopted different modes. 
We have briefly touched on some key issues concerning the judgment of a decision by process or by outcome. A most important factor that would determine the manner by which decisions are evaluated would depend on the global perspective adopted by the judge, as encapsulated in the three frameworks for decision making mentioned in the introduction - the gambling paradigm, the accountability model and the conflict model. We now examine the merits and drawbacks associated with each of the three perspectives. Our goal is to show the multiple-normatively, often unsupported—objectives held by realworld decision makers and their judges. Some readers may argue that, whatever the goal, it can be stated in terms of subjective expected utility. Because this decision-making model does not explicitly deal with conflict and accountability, we chose to discuss these models separately.

\section{THE ROLE OF PROCESS AND OUTCOME WITHIN THE GAMBLING PARADIGM}

The predominant framework within decision making has been the "gambling paradigm", the origins of which can be traced to early studies of gambling in the 17th century. The basic tacit assumption of this model is that any decision can be represented as a choice between gambles, with decision options expressed in terms of probabilities and utilities. It further assumes that the decision maker is a rational agent who will choose the option that offers the most advantageous bet.

Utility theory, which serves as the cornerstone of the gambling paradigm, was originally conceived as a normative theory, and therefore provides clear advice for evaluating decision quality. The guiding principle underlying this framework, as dictated by utility theory (e.g., Luce \& Raiffa, 1957; Schoemaker, 1982), is maximization of expected utility. A decision maker who follows this rule is expected to be consistent, thus fulfilling a basic tenet of a rational agent. Specifically, it provides an algorithm by which each option should be structured as a gamble, and includes a subjective utility assessment of the possible outcomes and the corresponding assessed probabilities for each outcome. The two components should be expressed numerically, so that their multiplication provides the subjective expected utility of a gamble.

According to utility theory, the decision maker should maximize subjective expected utility by selecting the option with the highest value. The theory is normative, because it postulates that strictly following the above algorithm will result in the best decision. Hence, a strict interpretation of utility theory implies that in the long run, decision quality can be equally assessed by either process or outcome. Unlike the conflict and the accountability models (treated below), the gambling paradigm provides, at least theoretically, an unambiguous standard for judging decision quality.

Broadly speaking, most decisions are based on three components: (1) obtaining relevant information (either from memory or from the external world), (2) construction of the problem (or decision) space and inserting the relevant information appropriately in the decision problem structure, and (3) assessing the values and likelihoods of different outcomes. Utility theory omits advice on how to conduct the first two stages, implying that there are no transparent criteria for evaluating the performance of the decision maker on these two facets. Decision analysis (von Winterfeldt \& Edwards, 1986) provides some guidelines regarding the elicitation of the relevant utilities and probabilities. However, it is not an inherent part 
of the theory, and whether the method really yields valid and consistent responses has not been established empirically.

There is ample research showing that the assessment of the relevant utilities and probabilities is subject to a large number of pitfalls. For example, utility theory adopts the philosophy of "articulated values" (Fischhoff, 1991), postulating that people possess welldifferentiated values (and thus, the only problem concerns reliable and accurate methods for eliciting these values). However, people's preferences are often unstable (Fischhoff, Slovic \& Lichtenstein, 1980; Slovic, 1995). A more realistic approach is expressed by the philosophy of "basic values", according to which people do not possess a priori values for most decision problems, except for a few broad and general principles (Fischhoff, 1991). According to this view, much of the observed instability in preferences can be accounted for by the fact that judgments and choices are most often made online, that is, during the process of elicitation (Slovic, 1995).

Valuations derived from basic values use inferential processes that are subject to different framing effects. For instance, beef described as 75 percent lean should, according to utility theory, be equally attractive if presented as 25 percent fat. However, diners under the first description reported a significantly higher eating pleasure (Levin \& Gaeth, 1988). Such framing effects violate utility theory's principle of procedure invariance, according to which preferences should not depend on the description of the options or the method of elicitation. It goes without saying that different frames may constitute a major source of discrepancy between the decision maker and the judge.

Beside the difficulties associated with assessment and measurement, the term "utility" remains vague, at least with regard to its temporal nature. Specifically, Kahneman, Wakker and Sarin (1997) proposed to distinguish between "remembered", "experienced" and "predicted" utility, thus referring to the past, the present and the future, respectively. This distinction has an important implication for our context: whereas the utility envisaged by a decision maker (at the time of making the decision) can be interpreted only in the last sense, namely, as a forecast, the judgment of the decision is based on either experienced or remembered utilities. Without knowing the decision maker's preferences, a decision is difficult to judge. If judges use their own preferences to assess decision quality, they may (at least in the view of the decision maker) erroneously condemn the decision. Attempting to reconstruct the decision maker's preferences is an extremely difficult task in itself. Moreover, it creates the danger that any decision can be justified, and deemed optimal—by constructing preferences not beforehand, as prescribed by the subjective expected utility model, but afterwards (Schoemaker, 1991).

Note that the judgment of decision quality within the gambling paradigm can be carried out in two fundamentally different ways. Under one approach, the judge would try to assess as accurately as possible the goals, values and utilities of the decision maker, judging whether the decision maker followed the basic maxims of rational behavior. Under an alternative approach, the judge's task is to evaluate not just the decision maker's rationality, but also whether the decision maker's goals and the utilities attached to different outcomes are "acceptable". 3

If we turn to the uncertainty component encapsulated in the utility model, subjective probabilities seem to be one of the less realistic features of utility theory, and of the gambling

\footnotetext{
${ }^{3}$ The term "acceptable" is obviously subjective and often ill-defined. Acceptability may be determined by social norms, or by the norms adopted by the judge.
} 
paradigm in general. In real life, probabilities are usually ambiguous and imprecise. Furthermore, extensive empirical research indicates that people are often poorly calibrated (e.g., Keren, 1991b), and that probability assessments are vulnerable to different biases (e.g., Kahneman, Slovic \& Tversky, 1982). For instance, as a result of the availability heuristic, salient outcomes are more likely to be remembered, and seem more likely to occur (Tversky \& Kahneman, 1973). At an even more fundamental level, people have strong preferences for deterministic definitive (yes/no) predictions (Keren \& Teigen, 2001), casting doubt on whether people think probabilistically at all.

Finally, there is overwhelming evidence that, contrary to one of the basic assumptions of utility theory, the assessments of utilities and probabilities are not independent (see Weber, 1994, for an excellent review). Current theorizing suggests that rank-order utilities may provide the best description of people's choice behavior. However, even if this description accurately describes the underlying choice processes, it is highly questionable whether people are entirely aware of it. ${ }^{4}$ Since rank-order dependence is not intuitive, it is doubtful whether judges of the decision process would adopt it in their judgment of the decision quality.

It is beyond the scope of the present chapter to provide even a brief evaluation of the pros and cons of the gambling paradigm in general, and of utility theory in particular. The question we are addressing here is the extent to which the gambling paradigm provides an adequate and sensible framework for the evaluation of decision quality.

The appealing aspect of the gambling paradigm as a basis for judging decision quality is that, unlike the other two models (treated below), it provides an apparently unambiguous procedure for evaluating decisions. However, as we noted already, because of their inherently subjective nature, there are serious difficulties associated with the assessment of both subjective probability and subjective utility.

The gambling paradigm, which largely relies on subjective expected utility theory, resembles a bookkeeping activity, in which the probabilities and utilities (and their products) of the different options are balanced against each other. In that respect, the gambling paradigm offers judges a convenient method by which they can evaluate the decision or the decision maker. Despite the measurement problems briefly reviewed above, it seems to be a neutral and systematic method by which decisions may be evaluated. In reality, however, people are not accountants, and bookkeeping is usually not the way by which they make their decisions. The gambling model may be adequate for some, but certainly not all, economic decisions. The most serious shortcoming of the gambling model may be its neglect of the emotional impact on the decision process (e.g., Lopes, 1987), specifically when the consequences are of major importance for the decision maker. It considers solely what Janis and Mann (1977) refer to as "cold" decisions. A judge who follows the conflict model, which is discussed next, will treat decisions as "hot"- - taking emotions into account.

\section{DECISION EVALUATION BY PROCESS OR OUTCOME-THE CONFLICT MODEL}

An alternative perspective to the one offered by the gambling paradigm is to view a decision between two (or more) options as a conflict resolution (Coombs, 1987). Janis and Mann

\footnotetext{
${ }^{4}$ If the principles associated with rank-dependent utility theory were transparent, it stands to reason that the originators of utility theory would probably be aware of it.
} 
(1977) were among the first to propose a framework in which conflict ${ }^{5}$ is central. Because choosing one option means giving up another, it implies an internal conflict in which the decision maker expects to experience regret regardless of what is decided. A decision can thus be described as a competition between different selves, each advocating one of the possible options.

Such an internal conflict may have the decision maker torn between normative considerations, on the one hand, and contradicting emotions, on the other hand (e.g., Sloman, 1996; Haidt, 2001). While the conflict model has no clear prescriptions and offers mainly a descriptive perspective, a judge who follows the conflict model understands that powerful emotions may, under some circumstances, override rational considerations. Although relatively little is known about how exactly emotions affect the decision process, ${ }^{6}$ it is nevertheless widely accepted that much behavior is (to some degree) non-volitional, even after substantial deliberations (e.g., Loewenstein, 1998).

Indeed, most judicial systems in Western culture would take into account the emotional circumstances under which a decision has been reached or an action conducted. A murder committed in cold blood will usually receive harsher punishment than one that "just happened" in the heat of the moment. This example illustrates that conflict-minded judges are not blind to the outcome of a decision. Circumstances may alleviate the harshness of the judgment, but not change its valence: killing is always wrong.

While emotions may compete with "rational" decision making, they may also contradict each other. A woman with a family history of breast cancer may experience conflicting anticipated and anticipatory emotions when considering whether to take a test for the breast cancer gene (e.g., Loewenstein et al., 2001). Anticipated emotions arise from the possible negative consequences, like those expected as a result of a positive test outcome (for example, the knowledge that one carries the gene). Anticipatory emotions are those experienced during the decision process, and they reflect the aversive feelings associated with uncertainty (for example, the possibility that one might, at some point, develop breast cancer). After a positive test outcome, anticipatory emotions can be so powerful that women with a family history of breast cancer decide to reduce their uncertainty by undergoing a preventive mastectomy.

The internal struggle evoked by a difficult decision may be described as an approachavoidance conflict (e.g., Miller \& Kraeling, 1953). While part of the decision maker may want to avoid the conflict (by procrastinating or shifting the responsibility to others), another part may want to "get it over with". Approach strategies include bolstering the chosen alternative by emphasizing its good aspects (Janis \& Mann, 1977), and taking the decision in small steps to make the responsibility seem less overwhelming (Sunstein \& UllmannMargalit, 1998). While "conflict model" judges may understand the emotions for both approach and avoidance, the first may be more effective in terms of reducing conflict in the long run. Moreover, people judging their distant past tend to harbor more regrets about inactions than those pertaining to actions (Gilovich \& Medvec, 1995).

Judges using the conflict model should also be aware that decision makers may change their minds as circumstances and related emotions change. For example, most pregnant

\footnotetext{
${ }^{5}$ In the present context, conflict refers exclusively to an internal conflict (or conflict between different selves). Conflict among two or more individuals (or organizations) is not considered here.

${ }^{6}$ Elster (1998) correctly notes that, by and large, most psychological studies on emotions have focused on the proximate or ultimate causes of the emotions, relatively undermining issues regarding how emotions generate behavior. Indeed, the latter is the more important facet of emotions relevant to judgment of decision quality.
} 
women prefer to avoid anesthesia during childbirth when asked one month before giving birth. However, during active labor, the preferences of many shifted toward avoiding pain. When they were evaluated one month postpartum, their preferences tended to return to avoiding anesthesia. Thus, the conflict between bearing the pain and maximizing the newborn's safety is resolved differently at various points in time (Christensen-Szalanski, 1984). Fear tends to increase as the time between the decision and the realization of the outcome gets smaller (Loewenstein et al., 2001).

Observing such inconsistencies in intertemporal choice may lead a judge who follows the gambling paradigm to conclude that the decision is an "anomaly" (Loewenstein \& Prelec, 1992). Even a judge following the conflict model may have difficulty in understanding the decision maker. After all, if the decision maker cannot predict, in foresight or in hindsight, the emotions experienced at the time of the decision, a judge may have even more difficulty in doing so.

Thus, considering emotions complicates decisions as well as the corresponding judgments of their quality. Under the conflict model, neither is as straightforward and unequivocal as is the case under the gambling paradigm. It is difficult to articulate any clear course of action for either decision maker or judge as to how decisions should be made except for general (and hence vague) guidelines. Decisions under the conflict model are often guided by what Damasio (1994) termed the "somatic marker", a sensational gut feeling (visceral and non-visceral) that may strongly affect both judgment and choice. For the present context, it is important to emphasize that even the decision maker will have difficulty in exactly articulating the somatic marker effects, let alone the judge.

Judges who adopt the conflict model may have difficulty in reliably reconstructing the emotional conditions and the particular internal conflict the decision maker was facing at the time of decision. It is generally difficult, sometimes impossible, to separate emotions from "rational" arguments, and decide on what should be their relative weights. Using the conflict model, then, is not as straightforward as the use of the gambling model.

\section{ACCOUNTABILITY-BY PROCESS OR BY OUTCOME}

Elster (1989) pointed out two opposing approaches in the social sciences that he referred to as Homo economicus and Homo sociologicus. The former is outcome-oriented and guided by considerations of instrumental rationality, as reflected in the gambling paradigm. The latter emphasizes the broader social context in which a decision takes place. Indeed, the (moral, social and legal) norms, conventions and traditions which constitute the cornerstones of the Homo sociologicus perspective play a central role in the assessment of decision quality. The accountability model, proposed by Tetlock and his associates (e.g., Tetlock, 1991; Lerner \& Tetlock, 1999), is a manifestation of the Homo sociologicus approach within the domain of decision making.

The accountability model posits that people do not face their decisions within a social vacuum (see Lerner \& Tetlock, 1999, for an overview), but rather as part of a social structure. Decision makers resemble politicians, because they depend on approval and respect from others to maintain their position. The ultimate goal of a decision, therefore, is satisfying or getting approval of "relevant" others and establishing a good reputation. They need to take regular "opinion polls" of the relevant audience's beliefs, and incorporate the results in their decisions. Bolstering may be used to frame the decision in terms of others' 
preferences - even if they are not actually taken into account. Emphasizing existing support from other groups may sway an audience to approve a decision.

The powerful effects of social influence on human decisions have been empirically demonstrated by two of the most seminal sets of experiments in the psychological sciencesthe conformity studies by Asch $(1951,1956)$ and the obedience studies by Milgram (1974). First, consider the experiments by Asch. He made his subjects believe that they were participating in a visual perception study. They were instructed to judge which of three lines was the same length as a standard line. The subject was seated together with a number of other participants (who were all confederates of the experimenter), and gave her judgment after the others. The differences between the three lines were sufficiently large so that, under normal conditions, they could be detected (practically) 100 percent of the time. On some of the trials, however, Asch instructed his confederates to give a wrong answer. His main finding was that a substantial number of his genuine subjects were unable to resist the group pressure and conformed by giving the wrong answer, too. From a strictly normative viewpoint, the decision to provide the incorrect answer should certainly be judged to be inappropriate. From a broader viewpoint, in judging decision quality, the circumstances under which the decision was made should not be ignored. ${ }^{7}$

The obedience experiments conducted by Milgram demonstrated that people find it difficult to disobey authority, even when its rules are unequivocally conflicting with universal moral norms. Specifically, participants were instructed to deliver electric shocks to a learner, whenever he made an error. Although the extreme laboratory setup employed by Milgram may be artificial, such situations are not entirely uncommon in real life. For example, should soldiers in the battlefield blindly accept the orders given to them by their commanders? ${ }^{8}$ Note that within the accountability framework a conflict may arise as to which authority the decision maker is accountable. This conflict may emerge either within or outside the organization. In the first case, the question may arise to which superior the decision maker is accountable, while in the second situation one may ask whether one is accountable to the organization (for example, the army) or to the larger community (in which case, the decision maker should act according to other norms). In judging a decision, a dispute may arise between the decision maker and the judge as to what authority the decision maker is accountable. Authority in this context should be interpreted in the broadest way: hence, a fundamental clash between the decision maker and the judge could arise because of disagreement about the appropriate authority for values and moral norms (for example, the authority of different religions).

More generally, it is important to realize whether the decision maker and the judge possess similar perspectives and share compatible views with regard to what constitutes a good decision. Decision makers who fail to understand a judge's beliefs may miss the opportunity to convince her. As a result of differences in jargon, knowledge base and social norms, interactions with people from backgrounds other than the decision maker's may lead to unfortunate misunderstandings. In order to be accountable, one may want to take the perspectives of the judges in order to assess their opinions. This requires decision makers to abandon, if only momentarily, their own perspective and be careful not to fall into the well-known confirmation bias (Wason, 1960) — the tendency to select information that confirms their own beliefs.

\footnotetext{
${ }^{7}$ Indeed, in a similar vein, most judicial systems (especially when determining the punishment) take into account the circumstances under which the decision to commit wrongdoing was made.

${ }^{8}$ The major argument of Adolf Eichmann, as well as many other Nazi war criminals, was that he simply followed orders from his superiors.
} 
The metaphor underlying the accountability model is that of politicians who should always be able to produce reasons to justify their choice to a judge. Thus, decisions under the accountability model are more likely to follow a reason-based than a rule-based mode (Shafir, Simonson \& Tversky, 1993).

In contrast to the gambling model, which is based on a strictly rational analytical reasoning mode, the accountability framework is more flexible, and arguments that are based on intuitive narrative considerations (e.g., Denes-Raj \& Epstein, 1994) are acceptable as long as they sound sufficiently convincing.

There are several aspects of the decision process that are highlighted within the accountability framework. First, a decision maker who is mainly motivated by accountability considerations would tend to examine the justification for each and every decision. Especially on decisions associated with important consequences, it will be difficult to justify poor outcomes by claiming that the decision strategy employed is the optimal one in the long run. A judge evaluating a decision would usually focus only on the current outcome. In other words, in most circumstances, judges of decisions would tend to adopt a clinical rather than a statistical or actuarial approach (e.g., Dawes, Faust \& Meehl, 1989), eventually leading to zero tolerance of errors, even when allowing errors may, in the long run, be the policy with the best results (Einhorn, 1986).

Decision makers sensitive to being accountable, may be particularly susceptible to certain heuristics and decision pitfalls. For instance, they may prefer the current status quo to a new course of action (Samuelson \& Zeckhauser, 1988), refrain from taking action, thus exhibiting the omission bias (e.g., Ritov \& Baron, 1990, 1992), and continue current projects even if they are no longer profitable—ignoring sunk costs (Arkes \& Blumer, 1985). ${ }^{9}$ Many people mistakenly feel that each of these strategies offers the "safer" decision. Because judges are also subject to these biases, following them may help decision makers to minimize the risks of being held accountable for any negative unwanted outcomes.

To be accountable, a decision maker should appear to be trustworthy. Building trust may increase the odds that the judge will exhibit an empathic attitude when evaluating the decision maker. Those in favor of impeaching President Bill Clinton focused on his lies about his affair with Monica Lewinsky—not on the affair itself. A main argument for impeachment was that trust in the president had been lost. A major component in the buildup of trust is intentionality (Snijders \& Keren, 2001). The problem with intentionality, especially in real-life situations, is that it is usually prone to a subjective judgment and can only be inferred.

\section{SUMMARY AND CLOSING COMMENTS}

By the time we completed this chapter, we asked ourselves whether we had made the correct decision in undertaking to write an essay about a diffused and controversial question. Examining the process by which we reached our decision, we thought that regardless of the difficulties involved, the issue is too central to be ignored, and thus we were willing to meet the challenge. (We omit here our considerations regarding the possible risk in terms of loss of reputation.) As far as the outcome is concerned, we leave the judgment to the reader.

\footnotetext{
${ }^{9}$ Hence, Senator Jeremiah Denton may have saved his position by stating that "to terminate a project in which $\$ 1.1$ billion has been invested represents an unconscionable mishandling of the taxpayers' dollars" (4 November 1981, quoted in Dawes, 1988).
} 
Our review survey suggests that there is no unequivocal answer to the question of how to judge decision goodness; in particular, whether it should be based on process or on outcome. It would depend on the perspective adopted by the decision maker and the judge in terms of goals, whether short- or long-term considerations are emphasized (among other things, whether one views the decision as a unique case or as one out of many similar repeated decisions), and on the implicit model underlying the decision. We briefly discussed three possible frameworks in which the decision can be made and judged. The gambling paradigm, with subjective utility theory at its core, prescribes that rational decision makers trade off the possible positive and negative consequences of options to match their preferences. The conflict model views decisions as a source of conflict, in which the major goal is to resolve it in a manner that would reduce tension and stress. The accountability framework sees decision makers as politicians wanting to maintain their position. A good decision therefore pleases relevant others. While each model takes a different approach to decision making, each highlighting specific aspects, they are not necessarily always incompatible. One common feature shared by all the three approaches is that decision makers should select the option that is most likely to serve their best interest—whether optimizing personal profit, reducing conflict or maintaining social support.

It should be emphasized that the three frameworks discussed in this chapter do not exhaust all possible views, and other paradigms or subtypes of paradigms are conceivable. For instance, the decision maker or the judge may adopt a "rule-based" view, according to which a decision is good when it conforms to certain "acceptable" rules of conduct. Another example refers to, the distinction between adapting a promotion or a prevention outlook (Higgins, 1998) may be a major source of discrepancies in judging decision quality.

The question of which model the judge (or the decision maker) should adopt is a question that obviously cannot be answered unequivocally. The major problem underlying the judgment of decision quality is largely a question of compatibility between the decision maker and the judge (who performs a second-order decision). There are two major facets for which the compatibility between the decision maker and the judge can be assessed. First, there is the question whether both employ similar frameworks in structuring the decision problem. For instance, discrepancies between the decision maker and the judge may arise if the former was motivated by emotional considerations associated with conflict, whereas the latter, in making her judgment, was solely guided by utility theory. Even a judge who uses the same model as the decision maker may not entirely understand the decision maker's position at the time the decision was made. It is difficult, if not impossible, to ignore outcome knowledge when attempting to assess in retrospect the decision maker's situation. Similarly, differences between the decision maker and the judge may come about from different interpretations of the decision problem at hand. Indeed, framing effects probably constitute the most ubiquitous phenomenon of decision making. Thus, gaps may simply result from different framing of the decision problem by the decision maker and the judge. Besides such "perceptual" discrepancies that can lead to diverging interpretations, differences may also stem from differences in the tacit assumptions underlying the conduct of communication, as has been convincingly shown by Schwarz (1998).

The second source of possible disagreements between the decision maker and the judge may stem from differences in their value systems. Decision-making theory, however, is not set up to deal with differences in tastes and values. Indeed, the three theoretical frameworks tacitly assume different basic principles and values. For instance, the gambling paradigm 
endorses consequentialism, which is not necessarily the ultimate criterion for the other two paradigms.

The above two issues lead to a fundamental question: what exactly is meant by a good decision? Students of decision making would correctly claim that examining decision quality should be restricted to the first facet, the way the problem has been structured and the extent to which this structuring lends itself to acceptable solutions given the decision maker's goals. In practice, however, decisions and judgments are often strongly influenced by the underlying basic value system. Hence, judgments along the two facets mentioned above may often be confounded. More specifically, the perspective adopted by judges to assess the first facet may be strongly biased by their stand on the second facet.

In this chapter, we briefly touched upon some of the central controversies associated with judging decision quality. Our inquiry leads us to conclude that there are no unequivocal standards or guidelines for judging decision quality. Like the sentence and the verdict of the courtroom, the judgment of decision quality may sometimes be controversial and not always withstand scrutiny. Whether the judgment is "reasonable" (and we are aware that, like decision quality, "reasonable" is not well defined) would depend not only on the final verdict, but also on the arguments that justify the verdict. At the end of the day, it is probably the case that, at least in practice, the justification of a decision or its judgment is mainly driven by the strength of the supporting arguments (Shafir et al., 1993). Such a conclusion is probably most compatible with the accountability model of decision making. The fact that those who assess and judge decision makers (for instance, committees assessing decisions made by societal decision makers) frequently adopt one or the other version of an accountability model should not be taken as normative evidence for the superiority of the model.

\section{REFERENCES}

Arkes, H.R. \& Blumer, C. (1985). The psychology of sunk cost. Organizational Behavior and Human Performance, 35, 129-140.

Asch, S.E. (1951). Effects of group pressure upon the modification and distortion of judgment. In H. Guetzkow (ed.), Groups, Leadership, and Men (pp. 177-190). Pittsburgh: Carnegie Press.

Asch, S.E. (1956). Studies of independence and conformity: A minority of one against a unanimous majority. Psychological Monographs, 70, 70.

Baron, J. (1994). Nonconsequentialist decisions. Behavioral and Brain Sciences, 17, 1-42.

Baron, J. \& Hershey, J.C. (1988). Outcome bias in decision evaluation. Journal of Personality and Social Psychology, 54, 569-579.

Christensen-Szalanski, J.J.J. (1984). Discount functions and the measurement of patients' values: Women's decisions during childbirth. Medical Decision Making, 4, 47-58.

Coombs, C.H. (1987). The structure of conflict. American Psychologist, 42, 355-363.

Coombs, C.H., Dawes, R.M. \& Tversky, A. (1970). Mathematical Psychology. An Elementary Introduction. Englewood Cliffs, NJ: Prentice-Hall.

Damasio, A.R. (1994). Descartes' Error: Emotion, Reason, and the Human Brain. New York: Avon Books.

Dawes, R.M. (1988). Rational Choice in an Uncertain World. San Diego, CA: Harcourt Brace Janovich.

Dawes, R.M., Faust, D. \& Meehl, P.E. (1989). Clinical vs. actuarial judgment. Science, 243, 16681674.

Denes-Raj, V. \& Epstein, S. (1994). Conflict between intuitive and rational processing: When people behave against their better judgment. Journal of Personality and Social Psychology, 66, 819-829. 
Edwards, W., Kiss, I., Majone, G. \& Toda, M. (1984). What constitutes “a good decision"? Acta Psychologica, 56, 5-27.

Einhorn, H. (1986). Accepting error to make less error. Journal of Personality Assessment, 50, $387-$ 395.

Einhorn, H.J. \& Hogarth, R.M. (1978). Confidence in judgment: Persistence of the illusion of validity. Psychological Review, 85, 395-418.

Elster, J. (1989). The Cement of Society: A Study of Social Order. Cambridge: Cambridge University Press.

Elster, J. (1998). Emotions and economic theory. Journal of Economic Literature, 36, 47-74.

Fischhoff, B. (1975). Hindsight $\neq$ foresight: The effect of outcome knowledge on judgment under uncertainty. Journal of Experimental Psychology: Human Perception and Performance, 1, 288299.

Fischhoff, B. (1991). Value elicitation: Is there anything in there? American Psychologist, 46, 835847.

Fischhoff, B. (1996). The real world: What good is it? Organizational Behavior and Human Decision Processes, 65, 232-248.

Fischhoff, B., Slovic, P. \& Lichtenstein, S. (1980). Knowing what you want: Measuring labile values. In Wallsten, T. (ed.), Cognitive processes in choice and decision behavior (pp. 117-141). Hillsdale, NJ: Erlbaum.

Frisch, D. \& Clemen, R.T. (1994). Beyond expected utility: Rethinking behavioral decision research. Psychological Bulletin, 116, 46-54.

Frisch, D. \& Jones, S.K. (1993). Assessing the accuracy of decisions. Theory and Psychology, 3, $115-135$.

Gilovich, T. \& Medvec, V.H. (1995). The experience of regret: What, when, and why. Psychological Review, 102, 379-395.

Goldsmith, R.W. \& Sahlin, N.E. (1982). The role of second-order probabilities in decision making. In P.C. Humphreys, O. Svenson \& A. Vari (eds), Analysing and Aiding Decision Processes (pp. 455467). Amsterdam: North-Holland.

Haidt, J. (2001). The emotional dog and its rational tail: A social intuitionist approach to moral judgment. Psychological Review, 108, 814-834.

Hershey, J.C. \& Baron, J. (1992). Judgment by outcomes: When is it justified? Organizational Behavior and Human Decision Processes, 53, 89-93.

Hershey, J.C. \& Baron, J. (1995). Judgment by outcomes: When is it warranted? Organizational Behavior and Human Decision Processes, 62, 127.

Higgins, E.T. (1998). Promotion and prevention: regulatory focus as a motivational principle. In M.P. Zanna (ed.), Advances in Experimental Social Psychology, 30, 1-46.

Higgins, E.T. (2000). Making a good decision: Value from fit. American Psychologist, 55, 1217-1227.

Janis, I.L. \& Mann, L. (1977). Decision Making: A Psychological Analysis of Conflict, Choice, and Commitment. New York: Free Press.

Jones, E.E. \& Nisbett, R.E. (1972). The actor and the observer: Divergent perceptions of the causes of behavior. In E.E. Jones, D.E. Kanouse, H.H. Kelley, R.E. Nisbett, S. Valins \& B. Weiner (eds), Attribution: Perceiving the Causes of Behavior (pp. 79-94). Morristown, NJ: General Learning Press.

Jones, S.K., Yurak, T.J. \& Frisch, D. (1997). The effect of outcome information on the evaluation and recall of individuals' own decisions. Organizational Behavior and Human Decision Processes, $71,95-120$.

Kahneman, D. \& Varey, C. (1990). Propensities and counterfactuals: The loser that almost won. Journal of Personality and Social Psychology, 59, 1101-1110.

Kahneman, D., Slovic, P. \& Tversky, A. (1982). Judgment Under Uncertainty: Heuristics and Biases. Cambridge: Cambridge University Press.

Kahneman, D., Wakker, P.P. \& Sarin, R. (1997). Back to Bentham? Explorations of experienced utility. Quarterly Journal of Economics, 112, 375-405.

Keeney, R.L. \& Raiffa, H. (1976). Decisions with Multiple Objectives: Preferences and Value Tradeoffs. NewYork: Wiley.

Keren, G. (1991a). Additional tests of utility theory under unique and repeated conditions. Journal of Behavioral Decision Making, 4, 297-304. 
Keren, G. (1991b). Calibration and probability judgments: Conceptual and methodological issues. Acta Psychologica, 77, 217-273.

Keren, G. (1996). Perspectives of behavioral decision making: Some critical notes. Organizational Behavior and Human Decision Processes, 65, 169-178.

Keren, G. \& Teigen, K.H. (2001). Why is $p=.90$ better than $p=.70$ ? Preference for definitive predictions by lay consumers of probability judgments. Psychonomic Bulletin and Review, 8 , 191-202.

Lerner, J.S. \& Tetlock, P.E. (1999). Accounting for the effects of accountability. Psychological Review, $125,255-275$.

Levin, I.P. \& Gaeth, G.J. (1988). How consumers are affected by the framing of attribute information before and after consuming the product. Journal of Consumer Research, 15, 374-378.

Lipshitz, R. (1989). "Either a medal or a corporal": The effects of success and failure on the evaluation of decision making and decision makers. Organizational Behavior and Human Decision Processes, 44, 380-395.

Lipshitz, R. (1995). Judgment by outcomes: Why is it interesting? A reply to Hershey and Baron: "Judgment by outcomes: When is it justified?" Organizational Behavior and Human Decision Processes, 62, 123-126.

Loewenstein, G. (1998). Out of control: Visceral influences on behavior. Organizational Behavior and Human Decision Processes, 65, 272-292.

Loewenstein, G. \& Prelec, D. (1992). Anomalies in intertemporal choice: Evidence and interpretation. Quarterly Journal of Economics, 107, 573-597.

Loewenstein, G., Weber, E., Hsee, C. \& Welch, N. (2001). Risk as feelings. Psychological Bulletin, $127,267-286$.

Lopes, L.L. (1981). Decision making in the short run. Journal of Experimental Psychology: Human Learning and Memory, 7, 377-385.

Lopes, L.L. (1987). Between hope and fear. The psychology of risk. In L. Berkowitz (ed.), Advances in Experimental Social Psychology (vol. 20, pp. 255-295). New York: Academic Press.

Luce, R.D. \& Raiffa, H. (1957). Games and Decisions. New York: Wiley.

Milgram, S. (1974). Obedience to Authority. New York: Harper and Row.

Miller, N.E. \& Kraeling, D. (1953). Displacement: Greater generalization of approach than avoidance in a generalized approach-avoidance conflict.

Redelmeier, D.A. \& Tversky, A. (1992). On the framing of multiple prospects. Psychological Science, 3, 191-193.

Ritov, I. \& Baron, J. (1990). Reluctance to vaccinate: Omission bias and ambiguity. Journal of Behavioral Decision Making, 3, 263-277.

Ritov, I. \& Baron, J. (1992). Status-quo and omission bias. Journal of Risk and Uncertainty, 5, 49-61.

Roese, N.J. \& Olson, J.M. (1995). What Might Have Been: The Social Psychology of Counterfactual Thinking. Mahwah, NJ: Erlbaum.

Samuelson, P.A. (1963). Risk and uncertainty: A fallacy of large numbers. Scientia, 98, 108-113.

Samuelson, W. \& Zeckhauser, R. (1988). Status quo bias in decision making. Journal of Risk and Uncertainty, 1, 7-59.

Savage, L.J. (1954). The Foundations of Statistics. New York: Wiley.

Schoemaker, P.J.H. (1982). The expected utility model: Its variants, purposes, evidence, and limitations. Journal of Economic Literature, 20, 529-563.

Schoemaker, P.J.H. (1991). The quest for optimality: A positive heuristic of science? Behavioral and Brain Sciences, 14, 205-245.

Schwarz, N. (1993). Cognition and Communication. Mahwah, NJ: Erlbaum.

Shafir, E., Simonson, I. \& Tversky, A. (1993) Reason-based choice. Cognition, 49, 11-36.

Simon, H. (1973). The structure of ill-structured problems. Artificial Intelligence, 4, 181-201.

Sloman, S.A. (1996). The empirical case for two systems of reasoning. Psychological Bulletin, 119, $3-22$.

Slovic, P. (1995). The construction of preference. American Psychologist, 50, 364-371.

Snijders, C. \& Keren, G. (2001). Do you trust? Whom do you trust? When do you trust? Advances in Group Processes, 18, 129-160.

Spranca, M., Minsk, E. \& Baron, J. (1991). Omission and commission in judgment and choice. Journal of Experimental Social Psychology, 27, 76-105. 
Sunstein, C.R. \& Ullman-Margalit, E. (1998). Second-order decisions. Discussion paper no. 178, Center for Rationality and Interactive Decision Theory, Hebrew University of Jerusalem.

Tetlock, P.E. (1991). An alternative metaphor in the study of judgment and choice: people as politicians. Theory and Psychology, 1, 451-475.

Tversky, A. \& Kahneman, D. (1973). Availability: A heuristic for judging frequency and probability. Cognitive Psychology, 5, 207-232.

von Winterfeldt, D. (1980). Structuring decision problems for decision analysis. Acta Psychologica, $45,71-93$.

von Winterfeldt, D. \& Edwards, W. (1986). Decision Analysis and Behavioral Research. Cambridge: Cambridge University Press.

Wason, P.C. (1960). On the failure to eliminate hypotheses in a perceptual task. Quarterly Journal of Experimental Economics, 12, 129-140.

Weber, E.U. (1994). From subjective probabilities to decision weights: The effect of asymmetric loss functions on the evaluation of uncertain outcomes and events. Psychological Bulletin, 115, 228-242.

Wohlstetter, R. (1962). Pearl Harbor: Warning and Decision. Stanford, CA: Stanford University Press. 
